\title{
A SELECTIVE AND SENSITIVE METHOD DEVELOPMENT AND VALIDATION BY LC-MS/MS APPROACH FOR TRACE LEVEL QUANTIFICATION OF THREE POTENTIAL GENOTOXIC IMPURITIES IN PANTOPRAZOLE SODIUM DRUG SUBSTANCE
}

\author{
Nelaturi Subbaiah ${ }^{1,3}$ *, Gopi Reddy Venkata Subba Reddy ${ }^{2}$, Nitesh Kanyawar ${ }^{3}$ \\ and Manish Gangrade ${ }^{3}$ \\ ${ }^{1}$ Department of Chemistry, S.R.N.B. Degree, and P.G. College, Badvel, \\ Kadapa-516 227, Andhra Pradesh, India. \\ ${ }^{2}$ Department of Chemistry, JNTUA College of Engineering, Pulivendula, \\ Kadapa-560 390, Andhra Pradesh, India. \\ ${ }^{3}$ Cipla Ltd, Analytical Research and Development, Bangalore-560 049, India. \\ *E-mail: subbareddy083@gmail.com
}

\begin{abstract}
A novel reverse-phase selective and sensitive liquid chromatography coupled with tandem mass spectrometric (LCMS/MS) method was developed and validated for the trace analysis of N-(4-hydroxyphenyl) acetamide (GTI-A), N-(4(difluoromethoxy) phenyl) acetamide (GTI-B) and 4-(difluoromethoxy)-2-nitroaniline (GTI-C) which are potential genotoxic impurities in pantoprazole drug substance. The optimized method utilizes a positive ion electrospray ionization in multiple reaction monitoring (MRM) detection modes with purosphere star RP 18 e (100 mm×4.6 mm, $3.0 \mu \mathrm{m})$ column. Solution-A was $0.1 \%$ formic acid in $1000 \mathrm{ml}$ of water used as a buffer and solution-B was acetonitrile. The flow rate was $1.0 \mathrm{~mL} / \mathrm{min}$ and gradient program was developed for rapid analysis and elution mode was monitored by a mass spectrophotometer. The method was validated as per International Conference on Harmonization (ICH) guidelines and the method capability for quantification was found to be $0.5 \mathrm{ppm}$ with respect to sample concentration of $1 \mathrm{mg} / \mathrm{mL}$ in pantoprazole sodium. The correlation coefficient obtained for all the three impurities was $>0.9997$ and the accuracy of the method was ranged between $96.3 \%$ and $104.3 \%$.
\end{abstract}

Keywords: Pantoprazole sodium, LC-MS/MS, Genotoxic impurities, Gradient program, multiple reaction monitoring (MRM)

(C) RASĀYAN. All rights reserved

\section{INTRODUCTION}

Pantoprazole sodium sesquihydrate (Fig.-1) is a proton pump inhibitor (PPI) drug that inhibits gastric acid secretion and it works on gastric parietal cells to irreversibly inhibit $(\mathrm{H}+/ \mathrm{K}+)$-ATPase function and suppress the production of gastric acid. Chemically it is 5-(difluoromethoxy)-2-[[(3,4-dimethoxy-2-pyridyl) methyl] sulfinyl] benzimidazole, sodium salt, sesquihydrate. It has an empirical formula C16H14F2N3NaO4S.1.5 $\mathrm{H}_{2} \mathrm{O}$ and molecular weight $432.37^{1}$. N-(4-hydroxyphenyl) acetamide (GTI-A), N-(4-(difluoromethoxy) phenyl) acetamide (GTI-B) and 4-(difluoromethoxy)-2-nitroaniline (GTI-C) (Fig.-1) chemicals are used in Pantoprazole sodium process at an early stage.

Starting materials, intermediates, process impurities, degradation impurities and by-products are often found as impurities during the synthesis of drug substances. Some of these known impurities are potential mutagens or carcinogens and genotoxic impurities are those have potential to cause cancer in humans. ${ }^{2,3}$ Keeping in view of its consequence, European Medicines Agency and ICH [ICH M7] have framed guidelines genotoxic impurities in the drug substance. ${ }^{4,5}$ These guidelines proposed a threshold limit of toxicological concern value $(1.5 \mu \mathrm{g} / \mathrm{day})$ of genotoxic impurities in the drug substance. GTI-A, GTI-B and GTI-C are potential carcinogens, this data would ascertain that the regulatory authorities may expect to control the levels of genotoxic impurities to be 6 $\mathrm{ppm}$ in the drug substance (assuming a $1.5 \mu \mathrm{g} / /$ day daily dose). The analytical instruments in pharmaceutical industries such as HPLC with UV detection and GC with FID detection should be employed as the standards in

Rasayan J. Chem., 10(4), 1080-1087(2017)

http://dx.doi.org/10.7324/RJC.2017.1041863 
first attempt for PGIs analysis and these methods were discussed by Klick ${ }^{6}$ and Valvo et al. ${ }^{7}$, but there are some drawbacks with above-mentioned techniques because probability of co-elution of other impurities at trace level can change analytical results. The advantage of LC-MS/MS method, MRM experiment was accomplished by specifying the parent mass of the compound for MS/MS fragmentation and then specifically monitoring for a single fragment ion. One could think of this operation as the SIM of a fragment ion. The specific experiment is known as a "transition" and can be written (parent mass $->$ fragment mass). Some of the articles published in LC-MS/MS technique. ${ }^{8-10}$ The literature survey related that some spectrometric methods were developed for the determination of pantoprazole sodium API. ${ }^{11-13}$ A method has been reported for the determination of 2chloromethyl-3,4-dimethoxy pyridine hydrochloride in pantoprazole API by RP-HPLC, GC-MS and LC/MS/MS. ${ }^{14,15}$ Based on the literature survey, no analytical method has been available for the determination of GTI-A, GTI-B and GTI-C at trace level quantification in pantoprazole sodium.

The main objective of current research article was undertaken to develop a selective, sensitive and accurate method development to achieve efficient separation between Pantoprazole and genotoxic impurities using LCMS/MS technique. This method was validated as per ICH guidelines ${ }^{16}$ in terms of the limit of detection (LOD), limit of quantification (LOQ), specificity, linearity, precision, recovery, and robustness.

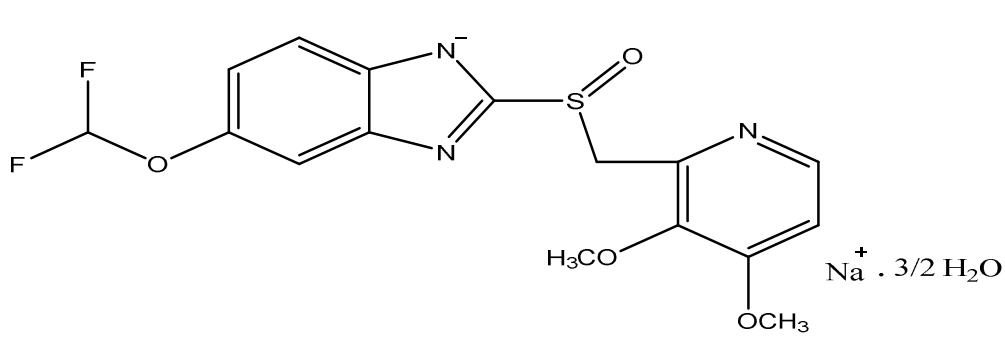

Pantoprazole sodium sesquihydrate

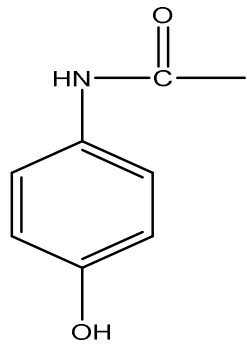

$N$-(4-hydroxyphenyl) acetamide (GTI-A)<smiles>CC(=O)Nc1ccc(OC(F)F)cc1</smiles><smiles>Nc1ccc(OC(F)F)cc1[N+](=O)[O-]</smiles>

4-(difluoromethoxy)2-nitroaniline (GTI-C)

$N$-(4-(difluoromethoxy) phenyl)acetamide (GTI-B)

Fig.-1: The chemical structure of Pantoprazole sodium sesquihydrate and genotoxic impurities

\section{Chemicals and Reagents}

\section{EXPERIMENTAL}

LCMS grade formic acid and acetonitrile were purchased from Merck (Mumbai, India). Purified water collected through Mill-Q plus water purification system (Millipore, Milford, MA, USA). Pantoprazole sodium sesquihydrate and genotoxic impurities were obtained from Cipla Ltd (R\&D), Bangalore, India.

\section{Instrumentation}

The MS of LC-MS/MS system used was Applied Bio system Sciex QTRAP-5500 model, Rotkreus, Switzerland. LC was carried out on Agilent HPLC (1200 series, Germany) with photodiode array detector. As part of experimentation, additional equipment such as PCI sonicator (22L500/CC/DTC), and precision analytical balance (MX5, Mettler Toledo, Schwerzenbach, Switzerland) were used. Data acquisition and processing were conducted using the Analyst 1.6.2 software on a Dell computer (Digital equipment Co). 


\section{Chromatographic conditions}

The chromatographic conditions were optimized with the analytical column Purosphere star RP 18 e $(150 \mathrm{~mm}$ $\mathrm{X} 4.6 \mathrm{~mm}, 3.0 \mu \mathrm{m})$. Solution-A was $0.1 \%$ formic acid in water and solution-B was acetonitrile. The mobile phase flow was operated in gradient mode for rapid analysis. The gradient program was set as follows: time $1 \%$ solution-A: 0/68, 6/68, 9/5, 12/5, 13/68 with equilibrium time of 4 minutes. The flow rate was $1.0 \mathrm{~mL} / \mathrm{min}$, with the flow rate split down from 1.0 to $0.4 \mathrm{ml} / \mathrm{min}$ into the ESI MS source. The column oven temperature was maintained at $25^{\circ} \mathrm{C}$ and sample cooler temperature was $20^{\circ} \mathrm{C}$. The injection volume was $10 \mu$. The positive ion electrospray ionization probe and multiple reaction monitoring (MRM) detection mode were used for LCMS/MS method. Mass spectrometer conditions were represented in Table-1.

Table-1: Mass spectrometer conditions

\begin{tabular}{l|l|l|l|l}
\hline \multicolumn{1}{c|}{ Parameter } & \multicolumn{1}{c|}{ Pantoprazole } & \multicolumn{1}{c|}{ GTI-A } & \multicolumn{1}{c}{ GTI-B } & \multicolumn{1}{c}{ GTI-C } \\
\hline $\begin{array}{l}\text { MRM monitoring for } \mathrm{m} / \mathrm{z} \\
\text { transition }\end{array}$ & $384.1>200.0$ & $152.1>110.0$ & $202.1>92.0$ & $205.1>137.0$ \\
Declustering potential (V) & 45 & & & \\
Entrance potential (V) & 12 & 30 & 60 & 50 \\
Collision energy (V) & 21 & 7 & 8 & 9 \\
Collision exit potential (V) & 18 & 22 & 32 & 24 \\
Ion spray voltage (V) & 5500 & 12 & 10 & 15 \\
Source temperature $\left({ }^{\circ} \mathrm{C}\right)$ & 450 & 5500 & 5500 & 5500 \\
Curtain gas flow (psi) & 40 & 450 & 450 & 450 \\
Ion source gas1 & 50 & 50 & 40 & 40 \\
Ion source gas2 & 50 & 50 & 50 & 50 \\
& & & 50 \\
\hline
\end{tabular}

\section{Sample and standard preparation}

The test concentration of pantoprazole sodium sesquihydrate was derived to $1 \mathrm{mg} / \mathrm{mL}$ based on mass detector response. The diluent was optimized as water and acetonitrile in the ratio of 50:50 (v/v). The standard solution of potentially genotoxic impurities was prepared with the different concentration of $0.5 \mathrm{ppm}, 3.0 \mathrm{ppm}, 4.5 \mathrm{ppm}$, $6.0 \mathrm{ppm}, 7.5 \mathrm{ppm}$ and $9.0 \mathrm{ppm}$ with respect to the test concentration.

\section{Method development}

\section{RESULTS AND DISCUSSION}

Initially, the trails were carried out using HPLC UV method with different phosphate and volatile buffers, methanol, and acetonitrile by isocratic and gradient mode. The attempts were failed to achieve the desired sensitivity and accuracy for the trace level of genotoxic impurities $(6 \mathrm{ppm})$. Hence to obtain the sensitivity the detection technique was changed from UV detector to Mass detector. Further, the development trials with LCMS/MS method was analyzed with different stationary phases which included C18, C8, C4, amide, amino, and cyano. In addition, different mobile phases such as formic acid, ammonium acetate, ammonium formate, acetic acid with the combination of acetonitrile and methanol have been tested for better optimisation of method. Chromatographic separation was finally attained on a purosphere star RP 18 e $(150 \mathrm{~mm} \mathrm{X} 4.6 \mathrm{~mm}, 3.0 \mu \mathrm{m})$, Solution-A was $0.1 \%$ formic acid in water and solution-B was acetonitrile. The mobile phase flow was operated in gradient mode for rapid analysis. The gradient program was set as follows: time/\%solution-A: 0/68, 6/68, 9/5, $12 / 5,13 / 68$ with equilibrium time of 4 minutes. The flow rate was $1.0 \mathrm{~mL} / \mathrm{min}$, column oven temperature was $25^{\circ} \mathrm{C}$, sample cooler temperature was $20^{\circ} \mathrm{C}$ and mass spectrometer parameter optimized to get maximum sensitivity for genotoxic impurities.

\section{Method validation}

\section{Specificity}

The specificity of the developed method was verified by injecting blank, individual potential genotoxic impurities (GTI-A, GTI-B and GTI-C) and pantoprazole sodium drug substance. No interference peak was observed at the retention time of GTI-A, GTI-B and GTI-C. The retention time of genotoxic impurities and 
pantoprazole was shown in Table-2. Specificity chromatograms are shown in the Fig.-2.

Table -2: Determination of specificity

\begin{tabular}{c|c|c}
\hline S. No. & Name & Retention time (min) \\
\hline 1 & GTI-A & 1.32 \\
2 & Pantoprazole & 2.70 \\
3 & GTI-B & 5.14 \\
4 & GTI-C & 8.58 \\
\hline
\end{tabular}

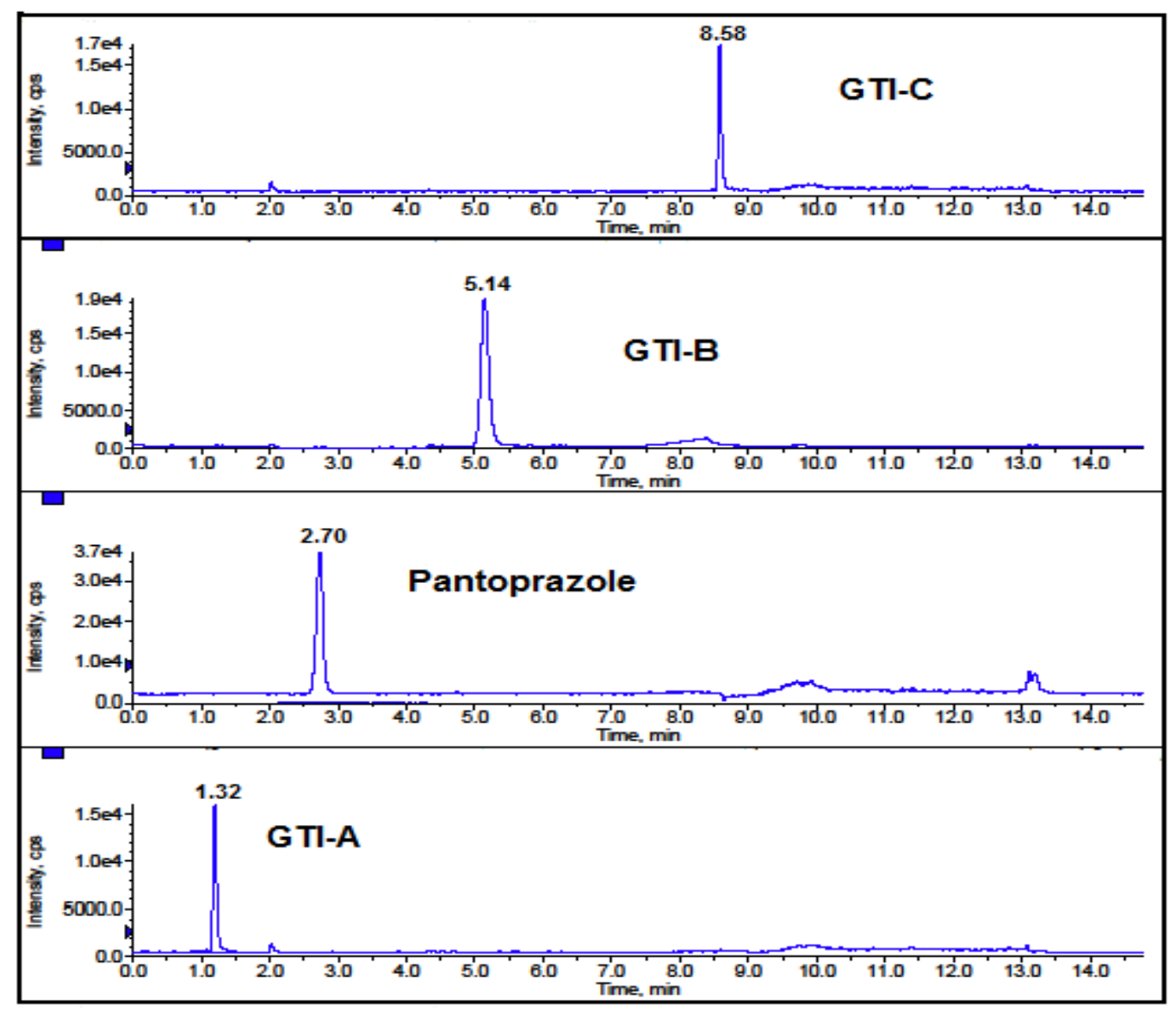

Fig.-2: Specificity chromatogram of pantoprazole and potential genotoxic impurities viz. GTI-A, GTI-B and GTI-C

\section{Determination of limit of detection (LOD) and limit of quantification (LOQ)}

To determine LOD and LOQ values of GTI-A, GTI-B and GTI-C, $10.0 \mathrm{ppm}$ solution of each impurity with respect to $1 \mathrm{mg} / \mathrm{mL}$ of pantoprazole sodium was injected. The concentration was reduced consecutively to achieve S/N (signal to noise) ratios of 3:1 and 10:1 respectively. The corresponding LOD and LOQ values were presented in Table-4.

\section{Linearity}

The linearity of the developed method was demonstrated with six-point calibration graph in the range of LOQ$150 \%$, i.e. $0.5 \mathrm{ppm}$ (LOQ), $3.0 \mathrm{ppm}(50 \%), 4.5 \mathrm{ppm}$ (75\%), $6.0 \mathrm{ppm}(100 \%$, limit level) and $9.0 \mathrm{ppm}(150 \%)$. The calibration curve was plotted for the peak areas ( $\mathrm{Y}$-axis) versus concentration (X-axis) of the analyte. The slope, intercept and correlation coefficient values were obtained from linear regression analysis. The linearity of the results showed an excellent between the peak areas and concentration of all three impurities. The corresponding linearity values and graph presented in Table-4 and Fig.-4. 


\section{Recovery}

Recovery studies by the standard addition method were performed. Recovery was accessed at LOQ, $3.0 \mathrm{ppm}$, $6.0 \mathrm{ppm}$ and $9.0 \mathrm{ppm}$ concentrations for all the three impurities with respect to $1.0 \mathrm{mg} / \mathrm{ml}$ pantoprazole sodium sample concentration. The three pure sample solutions of $1 \mathrm{mg} / \mathrm{mL}$ of pantoprazole sodium were injected, impurities were not detected. The results showed excellent recoveries for all three genotoxic impurities within the range of 96.3-104.3\%. The recoveries at such lower concentrations were satisfactory with $\% \mathrm{RSD}>4$. The recovery data presented in Table-3. Sample and recovery chromatograms at LOQ levels was shown in Fig.-3.

Table -3: Recovery for GTI-A, GTI-B and GTI-C using the proposed method

\begin{tabular}{c|c|c|c}
\hline \multirow{2}{*}{ Impurities concentration in ppm } & \multicolumn{3}{|c}{ \%Recovery of pure samples } \\
\cline { 2 - 4 } & Sample-I & Sample-II & Sample-III \\
\hline GTI-A & & & \\
$0.5 \mathrm{ppm}$ & $99.3 \pm 2.32$ & $97.3 \pm 2.67$ & $101.3 \pm 1.91$ \\
$3.0 \mathrm{ppm}$ & $97.7 \pm 1.74$ & $101.3 \pm 0.92$ & $98.7 \pm 1.09$ \\
$6.0 \mathrm{ppm}$ & $98.3 \pm 2.37$ & $102.3 \pm 1.32$ & $100.7 \pm 1.02$ \\
$9.0 \mathrm{ppm}$ & $101.1 \pm 1.12$ & $96.3 \pm 1.72$ & $98.8 \pm 1.97$ \\
GTI-B & & & \\
$0.5 \mathrm{ppm}$ & $99.9 \pm 2.41$ & $101.3 \pm 3.12$ & $96.7 \pm 1.72$ \\
$3.0 \mathrm{ppm}$ & $101.9 \pm 1.22$ & $98.3 \pm 1.72$ & $97.7 \pm 0.98$ \\
$6.0 \mathrm{ppm}$ & $103.3 \pm 1.09$ & $101.1 \pm 1.41$ & $98.7 \pm 2.12$ \\
$9.0 \mathrm{ppm}$ & $98.8 \pm 1.46$ & $102.0 \pm 0.92$ & $101.1 \pm 1.30$ \\
GTI-C & & & \\
$0.5 \mathrm{ppm}$ & $98.3 \pm 2.59$ & $99.0 \pm 1.62$ & $96.4 \pm 2.79$ \\
$3.0 \mathrm{ppm}$ & $96.7 \pm 0.62$ & $101.5 \pm 1.52$ & $102.3 \pm 1.95$ \\
$6.0 \mathrm{ppm}$ & $103.4 \pm 0.89$ & $104.3 \pm 1.82$ & $100.7 \pm 1.39$ \\
$9.0 \mathrm{ppm}$ & $101.9 \pm 1.02$ & $96.6 \pm 0.59$ & $101.0 \pm 1.77$ \\
\hline
\end{tabular}

${ }^{a}$ Mean value of three determinations

\section{System, method and intermediate precision}

System precision was studied by injecting six injections of GTI-A, GTI-B and GTI-C standard solution (6 ppm) at the limit level and the \%RSD was found to be less than $1 \%$. The method precision was studied by injecting the six independent solutions were $6.0 \mathrm{ppm}$ of GTI-A, GTI-B and GTI-C were spiked to pantoprazole sodium. Intermediate precision was accessed with the different column, a different instrument in a different day. The variation in the results was conveyed in terms of $\%$ RSD. The developed method was found to be precise as the $\%$ RSD values for repeatability precision was less than $3.0 \%$ and \% RSD values for intermediate precision was found to be less than $2.0 \%$ (Table-4).

Table-4: LOD, LOQ, linearity and precision data

\begin{tabular}{c|c|c|c}
\hline \multirow{2}{*}{ Parameter } & \multicolumn{3}{|c}{ Result } \\
\cline { 2 - 4 } & GTI-A & GTI-B & GTI-C \\
\hline LOD (ppm) & 0.15 & 0.15 & 0.15 \\
LOQ (ppm) & 0.5 & 0.5 & 0.5 \\
Linearity range (ppm) & $0.5-9$ & $0.5-9$ & $0.5-9$ \\
Correlation coefficient & 0.9997 & 0.9999 & 0.9998 \\
Slope & 58941 & 100899 & 80641 \\
Intercept & 5381 & -3218 & -4425 \\
Repeatability Precision (\%RSD $)$ & 0.89 & 2.11 & 1.93 \\
Intermediate precision (\%RSD $\left.{ }^{\mathrm{a}}\right)$ & 1.91 & 0.94 & 1.02 \\
\hline
\end{tabular}

${ }^{a}$ Mean value of six determinations

Robustness

Robustness of the method was determined by making slight and deliberate changes in experimental conditions. 
RASĀYAN J. Chem.

Vol. 10 | No. 4 |1080-1087 | October - December | 2017
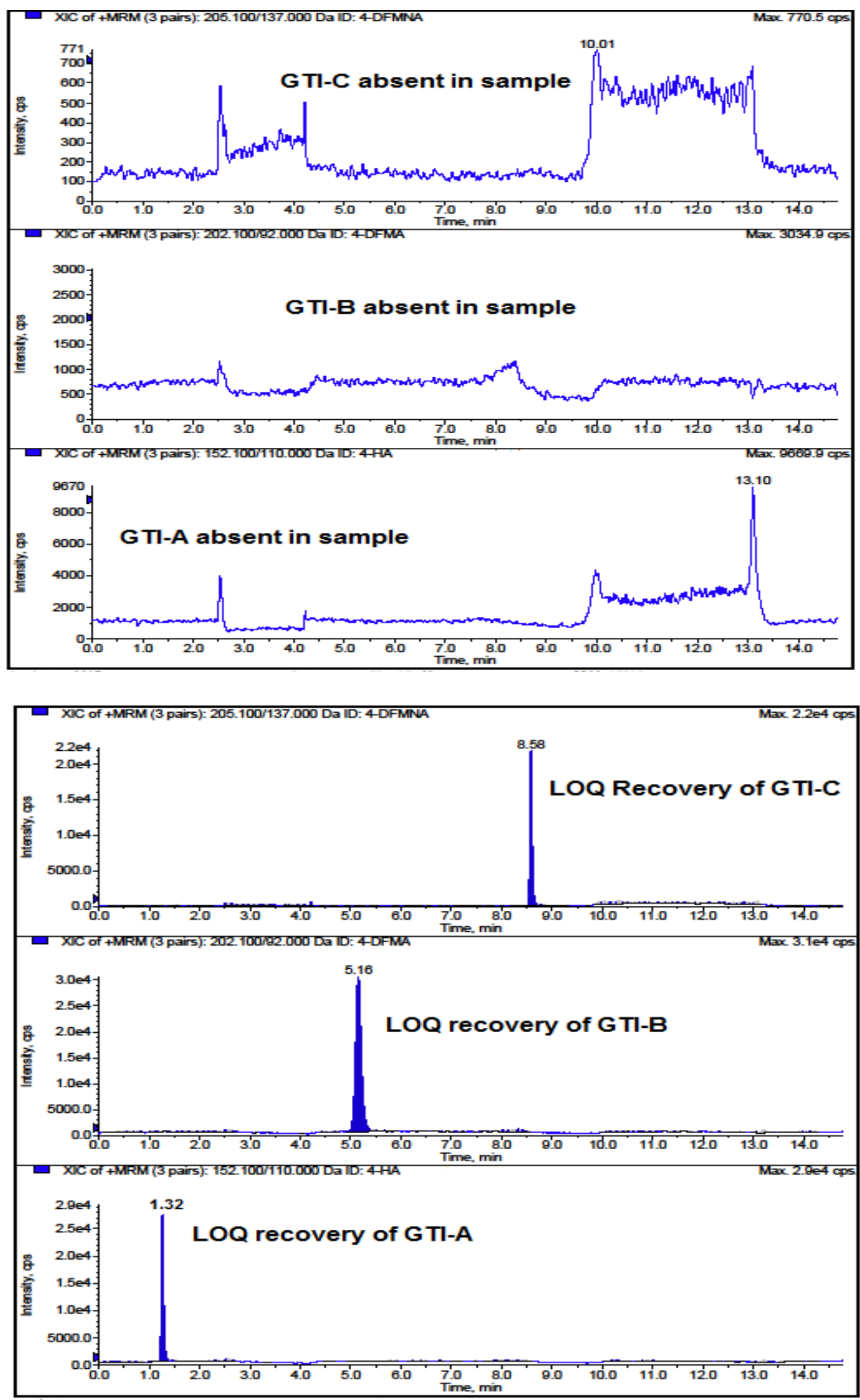

Fig.-3: Chromatogram of the sample (a) and recovery (b) at LOQ concentration level of three potential genotoxic impurities. 
RASĀYAN J. Chem.

Vol. 10 | No. 4 |1080-1087 | October - December | 2017

The flow rate of mobile phase was altered by 0.1 units i.e. 1.0 to $1.1 \mathrm{~mL} / \mathrm{min}, 1$ to $0.9 \mathrm{~mL} / \mathrm{min}$ and effect of temperature on the resolution was also studied at $23^{\circ} \mathrm{C}$ and $27^{\circ} \mathrm{C}$ (altered by 2 units). Test sample spiked with the standard at limit level $(6.0 \mathrm{ppm})$ was prepared and injected. \% RSD found to be less than 10 in all the conditions in each case.

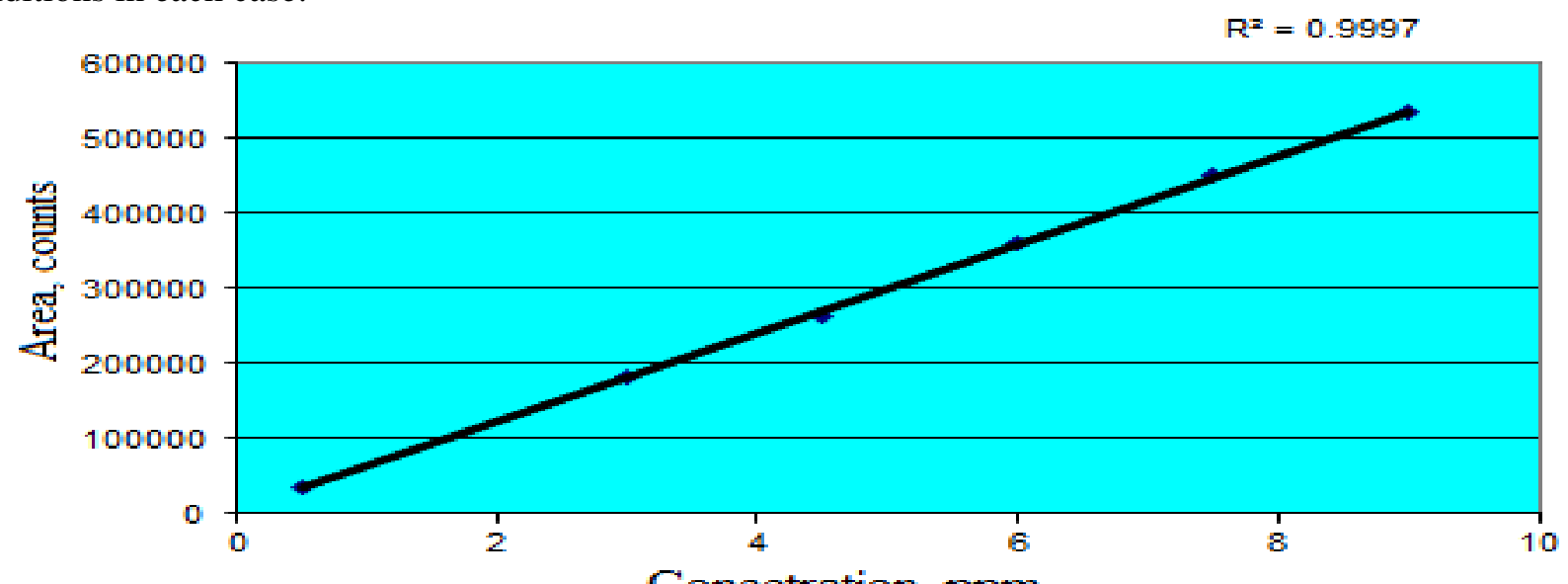

Concetration, ppm

Linearity graph for GTI-A

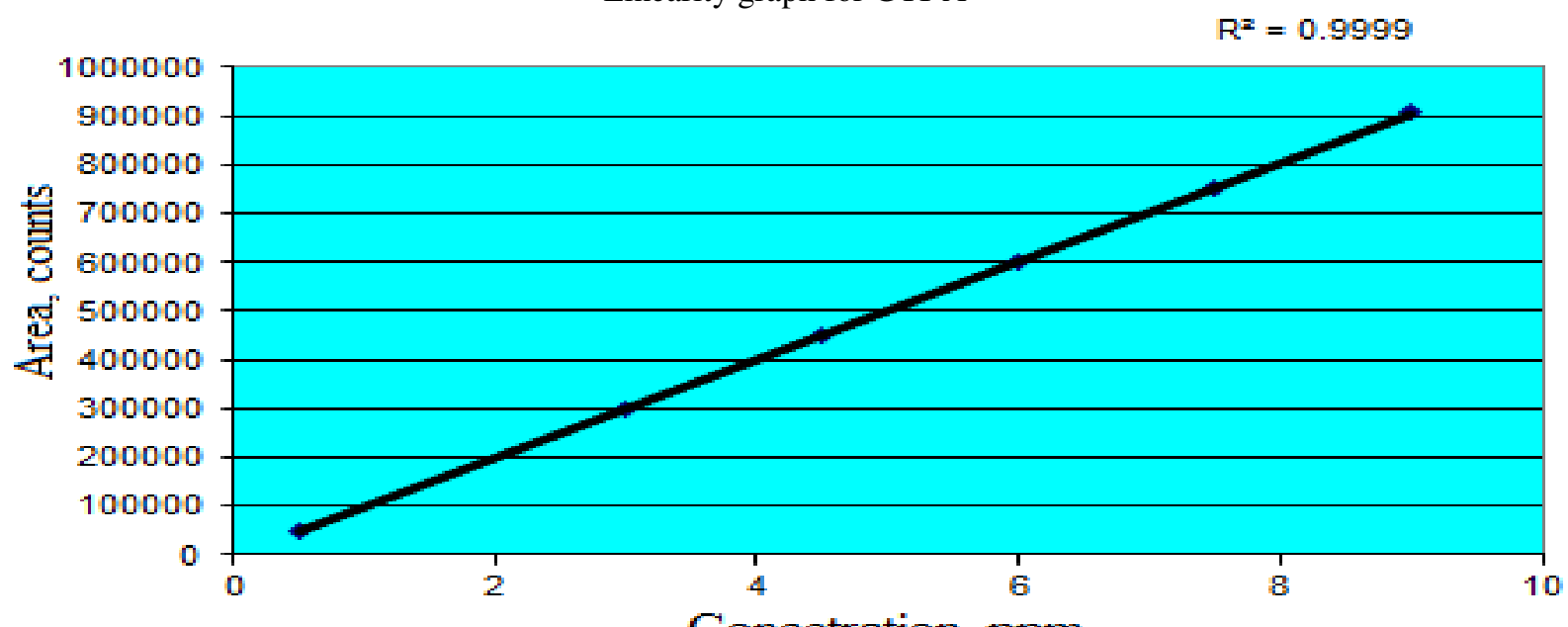

Concetration, ppm

Linearity graph for GTI-B

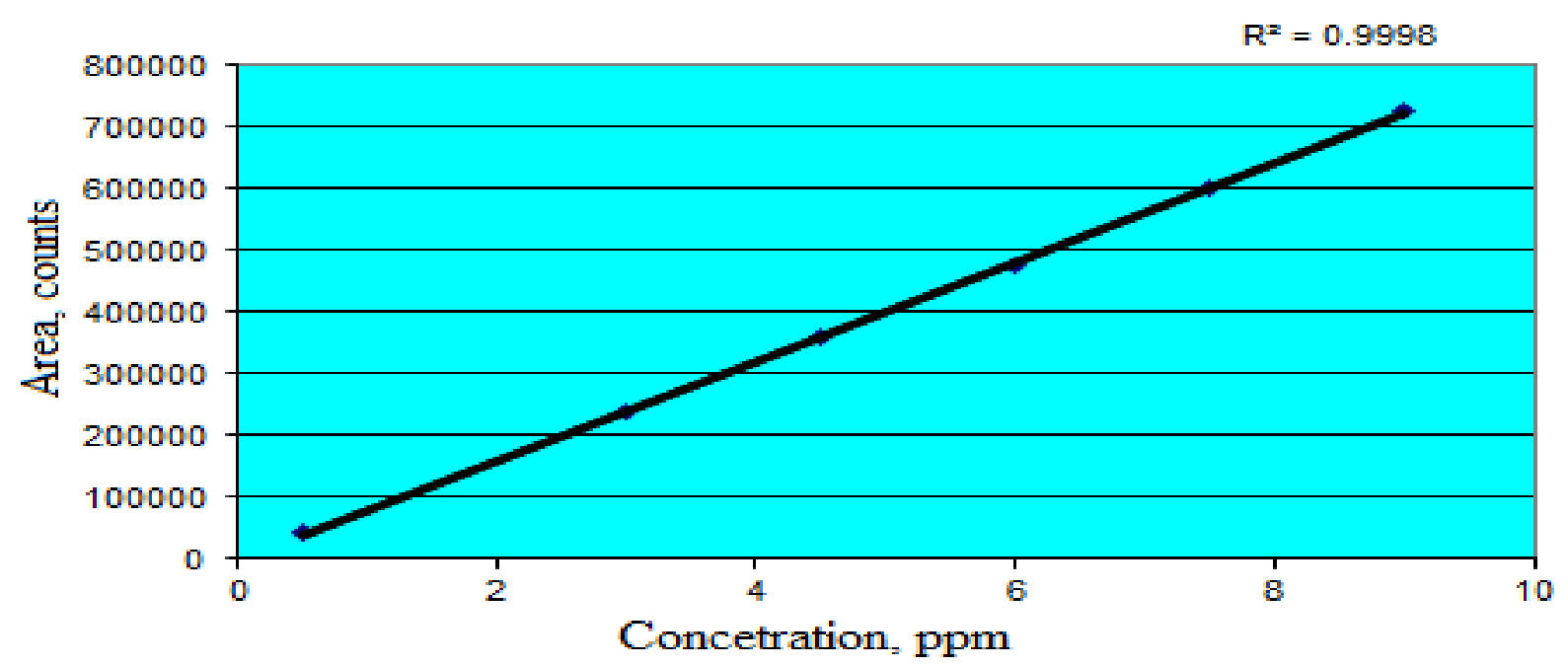

Linearity graph for GTI-C

Fig.-4: Linearity graph for GTI-A, GTI-B and GTI-C 
Stability of sample (Pantoprazole sodium) and standard solution (GTI-A, GTI-B and GTI-C))

The sample solution was prepared as per the proposed method. To this sample, GTI-A, GTI-B and GTI-C were quantitatively spiked at limit level concentration and stored at $20^{\circ} \mathrm{C}$. The spiked sample and standard solution limit level $(6 \mathrm{ppm})$ were injected into the system immediately and at various intervals. The $\%$ relative difference between method precision and solution stability study were calculated and found below 10 . This indicated that the sample solution and standard solution were found to be stable up to 34 hours at $20^{\circ} \mathrm{C}$.

\section{CONCLUSION}

A rapid gradient LC-MS/MS method has been developed for the simultaneous determination of three potential genotoxic impurities GTI-A, GTI-B and GTI-C in pantoprazole sodium drug substance. The developed method utilizes MRM mode for quantification which provided for better sensitivity and selectivity. The developed method was completely validated as per ICH guidelines and presents good linearity, specificity, accuracy, precision: a) system precision b) Repeatability and c) intermediate precision and robustness. The LOD and LOQ were quite satisfactory for the developed method. In addition to this method can be employed conveniently, consistency and successfully for the estimation of GTI-A, GTI-B and GTI-C for routine quality control release and stability studies in drugs and pharmaceuticals.

\section{ACKNOWLEDGEMENT}

The authors are grateful to the management of Cipla Limited, Bangalore for their support, encouragement to carry out research work.

\section{REFERENCES}

1. Pantoprazole monograph USP 40-NF 45, The United States Pharmacopeial Convention, 12601, Twinbrook Parkway, Rockville, MD, 20852, 5563.

2. H.M. Bolt, H. Foth, J.G. Hengstler, G.H. Degan, Toxicol Lett., 151, 29 (2004).

3. D. Jacobson-Kram, T. McGovern, Adv Drug Deliv Rev., 59, 38 (2007).

4. Guideline on the limits of genotoxic impurities, EMA guidance MEA/CHMP/QWP/251344/2006 and EMA/CHMP/SWP/431994/2007 Rev.3, 23 September 2010.

5. Guideline for Assessment and Control of DNA Reactive (Mutagenic) Impurities in pharmaceuticals to Limit Potential Carcinogenic risk, M7 ICH, 2014.

6. S. Klick, J. Pharm. Biomed. Anal., 13, 563 (1995).

7. L. Valvo, R. Alimenti, S. Alimonti, S. Raimondi, F. Foglietta, F. Campana, J. Pharm. Biomed. Anal., 15, 989 (1997).

8. A. Vijaya Bhaskar Reddy, N. Venugopal, G. Madhavi, K. Gangadhara Reddy, V. Madhavi, J. Pharm. Biomed. Anal., 84, 84 (2013).

9. A. Vijaya Bhaskar Reddy, J. Jaafar, A. Bin Aris, Z. Abdul mazid, K.Umar, J. Talib, G. Madhavi, J. Sep. Sci., 38, 2580 (2015).

10. S. K. Gudlawar1, Jaya Dwivedi and N. Venugopal, Rasayan J.Chem., 8 (1), 47 (2015).

11. N.V. Pimpodkar, R.S. Nalawade, B.S. Kuchekar, N.S. Mahajan, R.L. Jadhav, Int. J. Chem. Sci., 6, 993 (2008).

12. G. Madhusudhan Reddy, B. Vijaya Bhaskar, P. Pratap Reddy, S. Ashok, P. Sudhakar, J. Moses Babu, K. Vyas, K. Mukkanti, J. Pharm. Biomed. Anal., 45, 201 (2007).

13. R.B. Kakde, S.N. Gedam, N.K. Chadhary, A.G. Barsade, D.L. Kale, A.V. Kasture, Int. J. Pharm. Res., 1, 386 (2009).

14. V.V.S.S. Nanduri, K. Ratnakar Reddy, A.V.S.S. Prasad, K. Ramakrishna, J. Chromatogr., 68, 481 (2008).

15. N. Venugopal, A. Vijaya Bhaskar Reddy, K. Gangadhar Reddy, V. Madhavi, G. Madhavi, J. Pharm. Biomed. Anal., 70, 592 (2012).

16. Guidelines for Validation of Analytical Procedures, Q2 (R1), ICH, 1994.

[RJC-1863/2017] 